\title{
Fire Related Temperature Resistance of Fly Ash Based Geopolymer Mortar
}

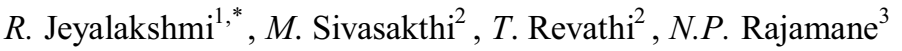 \\ ${ }^{1}$ Professor, Department of Chemistry, SRM University, Kattankulathur, 603 203, India \\ ${ }^{2}$ Research Scholar, Department of Chemistry, SRM University, Kattankulathur, 603203 India \\ ${ }^{3} \mathrm{Head}, \mathrm{CACR}$, SRM University, Kattankulathur, 603203, India
}

\begin{abstract}
The study presented in this paper is on the effect of heat treatment on fly ash based geopolymer mortar synthesized from fly ash (Class F -Low lime) using alkaline binary activator solution containing sodium hydroxide (18 M) and sodium silicate solution (MR 2.0), cured at $80 \mathrm{oC}$ for $24 \mathrm{~h} .7$ days aged specimen heated at elevated temperature $\left(200^{\circ} \mathrm{C}, 400^{\circ} \mathrm{C}, 600^{\circ} \mathrm{C}\right.$ and $\left.800^{\circ} \mathrm{C}\right)$ for the sustained period of $2 \mathrm{hrs}$. The TGA/DTA analysis and thermal conductivity measurement as per ASTM C113 were carried out besides the compressive strengths. The thermal stability of the fly ash mortar at elevated temperature was found to be high as reflected in the observed value of $f 800^{\circ} \mathrm{C} / \mathrm{f} 30^{\circ} \mathrm{C}$ being more than 1 and this ratio was raised to about 1.3 with the addition of $2 \%$ Zirconium di oxide $\left(\mathrm{ZrO}_{2}\right)$. No visible cracks were found on the specimens with and without $\mathrm{ZrO}_{2}$ when $800^{\circ} \mathrm{C}$ was sustained for $4 \mathrm{hrs}$ in smaller specimens of size: $50 \mathrm{~mm}$ diameter $\mathrm{x} 100 \mathrm{~mm}$ height and in also bigger size specimens: $22 \mathrm{~cm} \times 11 \mathrm{~cm} \times 7 \mathrm{~cm}$ ) specimens. TGA/DTA analysis of the geopolymer paste showed that the retention of mass was around $90 \%$. The addition of $\mathrm{ZrO} 2$ improved thermal resistance. The micro structure of the matrix found to be intact even at elevated temperature that was evident from the FESEM studies.
\end{abstract}

\section{Introduction}

Geopolymers (GPs) are systems of inorganic binders proposed by Prof Davidovits in 1970's [1] have emerged as an alternative to Ordinary Portland cement, with superior strength, durability and environmental performances. Geopolymer technology is opt for field applications in light of today's burning issues, i.e. sustainability and need for reduction of greenhouse gas emissions from cement-based industries which is contributing to about $7 \%$ of world $\mathrm{CO}_{2}$ emission. These inorganic alumino-silicate polymers can be synthesized from alkali activation of any material rich in silica and alumina. The reported investigations are on use of the precursor materials like metakaolin of geological origin or industrial by-products such as fly ash, blast furnace slag, red mud and rice husk ash and are activated using hydroxides of $\mathrm{Na}$ or $\mathrm{K}$ or in combination with silicates of $\mathrm{Na}$ or $\mathrm{K}$. The

\footnotetext{
* Corresponding author: author@email.org
} 
choice of the geopolymeric source materials (GSM) depends on availability, cost and type of applications. Extensive studies reported on GPs using metakaolin, fly ash and GGBS independently as sole precursors and tried to elucidate the kinetics, mechanisms and microstructure [2-7]. Geopolymers possess polymeric silicon-oxygen-aluminium three dimensional materials containing variety of amorphous to semi-crystalline phases, exhibit higher mechanical strength, much more excellent chemical, fire and heat resistances, compared to that of ordinary Portland cement [8-9]. Heat resistant properties of metakaoline based GPs were investigated and its thermal stability upto $1200-1400^{\circ} \mathrm{C}$ was reported. Heat resistant properties of alkali activated fly ash were investigated by several workers [10-15] and geopolymeric paste indicated high shrinkage as well as large changes in compressive strength at elevated temperature in the range $800-1200^{\circ} \mathrm{C}$. To improve thermal resistance, alternate GSMs such as mine tailings, waste ceramics were tried and satisfactory thermo stable geopolymeric paste was obtained [16-17].

In the present study to achieve fire temperature resistance geopolymers, zirconium di oxide $\left(\mathrm{ZrO}_{2}\right)$, as a refractory additive was included in high alkali activation of fly ash geopolymerisation reactions. Thermal properties, TGA/DTG, thermal conductivity and thermal expansion studies were conducted and the results were presented/discussed here.

\section{Materials and methods}

\subsection{Materials}

Fly ash (FA) sample from a local Thermal Power Plant was used. To prepare activating solution, called AAS, the materials used were: industrial grade sodium silicate solution $\left(15 \% \mathrm{Na}_{2} \mathrm{O}, 33 \% \mathrm{SiO}_{2}\right.$ and $52 \% \mathrm{H}_{2} \mathrm{O}$ : molar ratio $-\mathrm{SiO}_{2} / \mathrm{Na}_{2} \mathrm{O}=2.2$, lye $(50 \% \mathrm{NaOH})$ and deionized water. Mixture of sodium silicate and sodium hydroxide, as AAS was kept for $24 \mathrm{hrs}$ in order to cool it to room temperature. AR grade $\mathrm{ZrO}_{2}$ was used as an additive. Natural river bed sand (conforming to Grading Zone II of IS 383: 1970) used as fine aggregate had specific gravity of 2.58 and fineness modulus of 3.01 .

\subsection{Experimental procedures.}

The materials were weighed accurately using digital balances. Sand and Fly Ash were first dry mixed for about 3 minutes in a digital mortar mixer till a uniform mix is achieved. Then, the AAS of required quantity was poured into it and the mixing continued for further 7 minutes until a uniform fresh mortar mix was achieved. The fresh mix was then placed into plastic cylindrical moulds of size $50 \mathrm{~mm}$ diameter $\mathrm{x} 100 \mathrm{~mm}$ height in three equal layers and compacted using a laboratory vibrator. After $24 \mathrm{hrs}$ of casting, the cylindrical moulds, containing geopolymer matrix, were kept for heat curing at $80^{\circ} \mathrm{C}$ for a period of $24 \mathrm{hrs}$ in a hot air oven. The specimens taken out of the oven were allowed to cool to room temperature before demoulding operations were carried out. Specimens were then heat treated in a high temperature furnace (capacity $1400^{\circ} \mathrm{C}$, rate of heating $5^{\circ} \mathrm{C} / \mathrm{min}$ ) for $2 \mathrm{hrs}$ at $200^{\circ} \mathrm{C}, 400^{\circ} \mathrm{C}, 600^{\circ} \mathrm{C}$ and $800^{\circ} \mathrm{C}$. After the required high temperature is attained, the furnace was maintained for $1 \mathrm{hr}$ and then, it is switched off and the specimens were allowed to cool to room temperature. The compressive strength of the geopolymer mortars were measured using a CTM with the force applied at a rate of $2 \mathrm{KN} / \mathrm{s}$. Compressive strength gains or losses of the calcined specimens were then computed. The results reported here are the average of 5 replicates. 
Thermal Analysis (STA) [NETSCH 2500 Regulus] was used to study the thermal stability in the temperature range $30-1200^{\circ} \mathrm{C}$ in floating Air/Nitrogen $(60 \mathrm{ml} / \mathrm{min})$ with the heating rate of $10^{\circ} \mathrm{C} / \mathrm{min}$. Thermal conductivity of Mortar was examined by hot wire method according to the ASTM standard code C1113M-09 (Thermal conductivity apparatus - $\left.\mathrm{VBCC} / \mathrm{TCF} / 1400^{\circ} \mathrm{C}-04\right)$ using the specimen size $(22 \mathrm{~cm} \mathrm{X} 11 \mathrm{~cm} \mathrm{x} 7 \mathrm{~cm})$. The required temperature was reached by the heating rate of $10^{\circ} \mathrm{C}$ per minute and the uniform temperature throughout the sample was maintained by holding the sample for $4 \mathrm{hrs}$ at the same temperature.

Dilatometer measurements were conducted with specimens of size: $50 \mathrm{~mm}$ diameter $\mathrm{x}$ $100 \mathrm{~mm}$ height in the stainless steel mould placed horizontally in the dilatometer tube. Coefficient of thermal expansion at different temperatures were measured by push rod dilatometer method according to the ASTM standard E228-11(Computerized dilatometer $\left.\mathrm{VBCC} / \mathrm{DIL} / 1000^{\circ} \mathrm{C} / 13 / 14\right)$. The specimens were heated upto $800^{\circ} \mathrm{C}$, in the stepwise heating rate of $5^{\circ} \mathrm{C}$ per minute and allowed to reach thermal equilibrium at selected temperature before the length changes were recorded.

Scanning Electron Microscopy (Qunata) under vacuum mode using polished samples was utilised for microstructure characterization.

\section{Results and discussion}

\subsection{Composition of Fly ash}

Chemical composition of FA sample having sum of oxides $\mathrm{SiO}_{2}, \mathrm{Al}_{2} \mathrm{O}_{3}$ and $\mathrm{Fe}_{2} \mathrm{O}_{3}$ exceeded $80 \%$ and low content of $\mathrm{CaO}$ (less than $5 \%$ ) is in accordance with Class $\mathrm{F}$ defined in ASTM C 618. The total chemical composition of Fly ash, alkaline activator solution used in the sample preparation with geopolymer mortar are given in the Table1 and Table 2. Fly ash mix with Zirconium di oxide at $2 \%$ is designated as FAGP2z.

Table 1. Properties and chemical composition of Fly Ash (EDXRF analysis).

\begin{tabular}{|c|c|c|c|}
\hline \multicolumn{2}{|c|}{ Physical Properties } & \multicolumn{2}{c|}{ Chemical composition (wt. \%) } \\
\hline Specific Gravity & 2.15 & $\mathrm{CaO}$ & 2.09 \\
\hline Fineness (Blaine) & $330 \mathrm{~m}^{2} / \mathrm{kg}$ & $\mathrm{SiO}_{2}$ & 47.55 \\
\hline Bulk density & $1005 \mathrm{~kg} / \mathrm{m}^{3}$ & $\mathrm{Al}_{2} \mathrm{O}_{3}$ & 33.45 \\
\hline Residue on 45 micron sieve & $35 \%$ & $\mathrm{Na}_{2} \mathrm{O}$ & 0.4 \\
\hline $\begin{array}{c}\text { Cementing Efficiency Factor at } 28 \\
\text { day }\end{array}$ & 0.93 & $\mathrm{~K} 2 \mathrm{O}$ & 1.65 \\
\hline $\begin{array}{c}\text { Loss on Ignition } \\
\text { nyyy}\end{array}$ & $1.4 \%$ & $\mathrm{MgO}_{2}$ & 0.8 \\
\cline { 2 - 4 } & & $\mathrm{Fe}_{2} \mathrm{O}_{3}$ & 10.17 \\
\hline
\end{tabular}


Table 2. Mix ID and composition of alkaline activating solution (AAS).

\begin{tabular}{|c|c|c|c|c|c|c|c|c|}
\hline \multirow{2}{*}{$\begin{array}{c}\text { GPM } \\
\text { mix ID }\end{array}$} & \multirow{2}{*}{$\%$ FA } & \multirow{2}{*}{$\% \mathrm{ZrO}_{2}$} & \multirow{2}{*}{$\%$ FA } & \multicolumn{3}{|c|}{ AAS Content (wt \%) } & \multirow{2}{*}{$\begin{array}{c}\text { Fly Ash } \\
\text { /AAS } \\
\text { ratio }\end{array}$} & \multirow{2}{*}{$\begin{array}{l}\text { FA: } \\
\text { Sand }\end{array}$} \\
\hline & & & & $\mathrm{Na}_{2} \mathrm{O}$ & $\mathrm{SiO}_{2}$ & $\mathrm{H}_{2} \mathrm{O}$ & & \\
\hline FAGP1 & 100 & 0 & 100 & 21.5 & 12 & 66.5 & 0.55 & \\
\hline FAGP2 & 100 & 0 & 100 & 26 & 21 & 53 & 0.60 & $1: 2$ \\
\hline FAGP2z & 100 & 2 & 100 & 26 & 21 & 53 & 0.60 & \\
\hline
\end{tabular}

\subsection{High temperature property}

The compressive strengths of the mortar prepared at room temperature and at elevated temperature were measured. Strength development at different curing ages was followed and strength at 14days $\left(f_{R}\right)$ has been taken as a reference for calculating the strength retention $\left(f_{T} / f_{R}\right)$ at $T$ temperature exposure. It may be generally said that the strength of alkali-activated fly ash is influenced by the modulus (MS) and the concentration of $\mathrm{Na}_{2} \mathrm{O}$ in the alkaline activator, where the optimum performance was achieved at $\mathrm{Na}_{2} \mathrm{O}$ concentration of 7 to $10 \%$ and at MS of 0.6 to 1 . The curing conditions are the dominant factor controlling the strength of fly ash geopolymer. In our present study, it was observed that the specimens with $100 \%$ FA as source materials did not have any mechanical strength when AAS contained $\mathrm{NaOH}$ of $3.5 \mathrm{M}$ concentration; the addition of ceramic additive was also found to be ineffective. However, when the concentration of the $\mathrm{NaOH}$ solution in AAS was increased to 5M, (FAGP1) there was significant strength at ambient conditions; but, the test specimens lost most of their strengths after exposure to $800^{\circ} \mathrm{C}$. The specimens (FAGP 2) with AAS containing $\mathrm{NaOH}$ solution of concentration $10 \mathrm{M}$ showed room temperature strength similar to that achieved with (FAGP1) $5 \mathrm{M} \mathrm{NaOH}$ solution in AAS.

The relative increase or decrease in the compressive strength of each specimen as compared to its original strength before heating for the mortars as shown in Figure 1. The strength gain occurred with and without addition of zirconia, $\mathrm{ZrO}_{2}$, with the increase of alkali concentrations at all the studied temperature range.

Visual observations showed that all specimens reacted well having smooth surface and showed no visible cracks in heated specimen. The reported literature on fly ash base geopolymer activated by hybrid activator in the similar reaction conditions showed that geopolymer paste, mortar and concrete strength level at ambient conditions are approximately same but under thermal treatment, paste underwent $73 \%$ residual loss and mortar did not retain any residual strength above $600 \mathrm{C}$, even they split into two halves [15]. In our present study, the strength of geopolymer mortar specimens increased as temperature increased, attaining a peak strength at $200{ }^{\circ} \mathrm{C}$. Subsequently, this strength was observed to deteriorate slightly for the remainder of the heating regime but maintaining the $80 \%$ strength gain to that of unheated mortar; this may be due to stronger thermal compatibility and/or sintering effect by unreacted fly ash particle. In general, the strength gain phenomenon after thermal treatment observed in small size specimens of cement or geopolymer matrixes are no longer evident in the larger size specimens. There is always greater difference in thermal gradient between hotter exterior and cooler interior of these larger specimens. Mostly thermal gradients increase with increasing size, which consequently induces thermal cracking. 
The heat treatment of FAGP 2 specimens of size $22 \mathrm{~cm} \mathrm{x} 11 \mathrm{~cm} \mathrm{x} 7 \mathrm{~cm}$ casted to $800^{\circ} \mathrm{C}$ for sustained period of $4 \mathrm{hrs}$ did not show any visible surface changes.

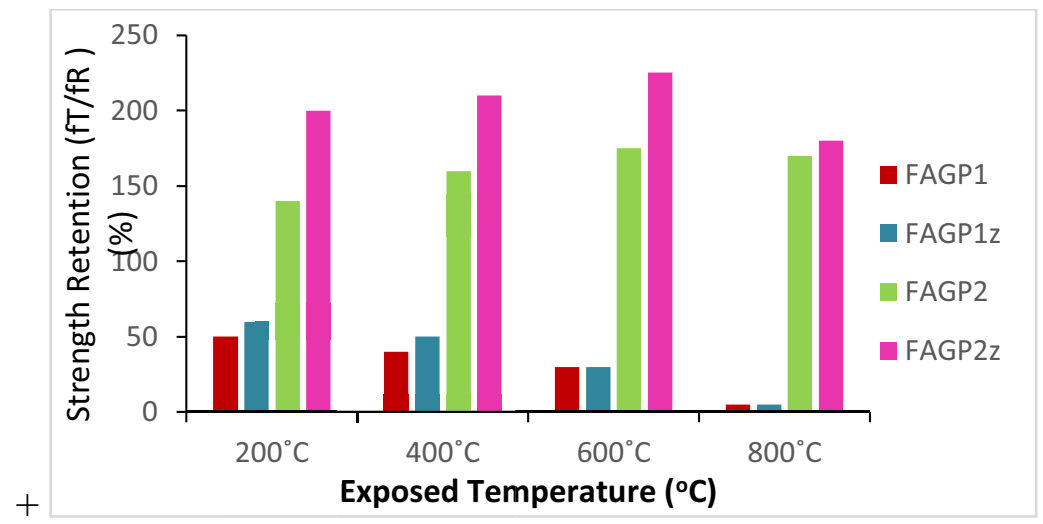

Fig. 1. Compressive Strength retention of geopolymer mortar after thermal treatment.
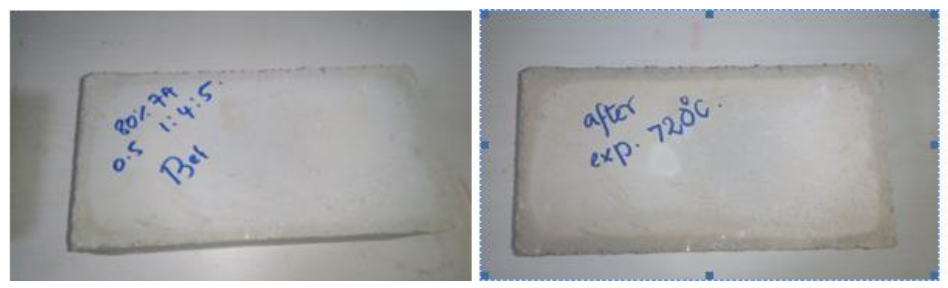

Fig. 2. Specimens before and after exposure to elevated temperature.

The integrity of matrix had not been affected (Figure 2), no peeling and even no cracks on the surface of the specimen after fire temperature. The water released from the geopolymerisation reaction trapped in the matrix is expelled at slower rate due to higher surface tension in the larger specimens.

\subsection{Thermal analysis TGA/DTG}

Figure 3 show the TGA analysis of geoplymer paste of the powedered specimens. In this TGA test, the mass loss was measured while the specimens were gradually exposed to increasing temperatures. Powdered specimens were used in TGA to ensure the achievement of thermal equillibrium during transient heating. TGA thermogram of mixes FAGP1 and FAGP2 showed that sharp decrease in weight before $250^{\circ} \mathrm{C}$ which is attributed to the loss of evapourable water content. After the initial rapid down, the rate of weight loss stabilised between $250^{\circ} \mathrm{C}$ to $780^{\circ} \mathrm{C}$. After $780^{\circ} \mathrm{C}$, little change in weight has occurred. After $1300^{\circ} \mathrm{C}$ exposure of geopolymer paste without addition of $\mathrm{ZrO}_{2}$, the total weight loss was $12 \%$ only and retained was around $88 \%$ for both FAGP2 whereas with the addition of zirconia in FAGP 2 z, residual mass was found to be $90 \%$. TG curve of FAGP2z was found to be smooth in nature. Similar TG analsis of ordinary portland cement paste showed that retention of mass was around $70 \%$ and visible crack of mortar specimen occurred around $400^{\circ} \mathrm{C}$.

The decrease in weight at around $120^{\circ} \mathrm{C}$ indicted by the DTA endothermic curve is due to the dehydration of water molecule. The endothermic peak from the ambient temperature 
to $180^{\circ} \mathrm{C}$ and centred at approximately $67^{\circ} \mathrm{C}$, may be due the dehydration of water correspondingly the weight loss of approximately $8 \%$ and is the dominant loss the whole heating regimen. The exothermic peak abserved at $337^{\circ} \mathrm{C}$ and $686^{\circ} \mathrm{C}$ may be due to ordering of Ferric oxide present in the fly ash. The $\mathrm{ZrO}_{2}$ addition does not alter the thermogram except the weight loss due to the evapouration of water absorbed on the surface during the reaction. DTA derivative curves were found to be very smooth indicate that there was no thermal reaction in the matrix with $\mathrm{ZrO}_{2}$ till $1200^{\circ} \mathrm{C}$.

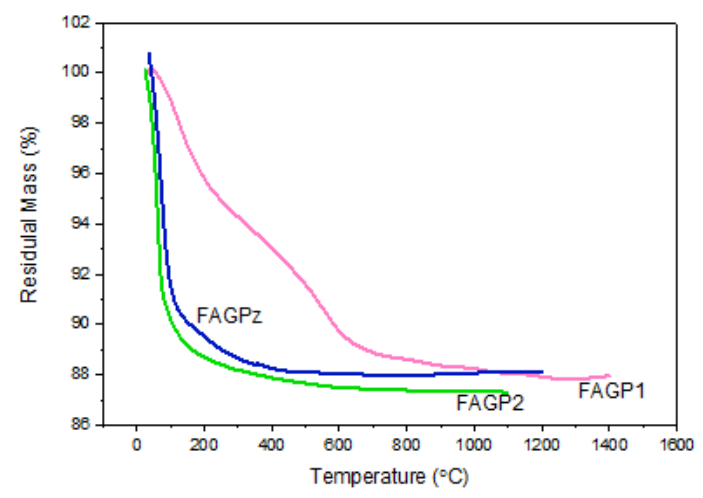

Fig. 3. TGA thermogram of the geopolymer paste.

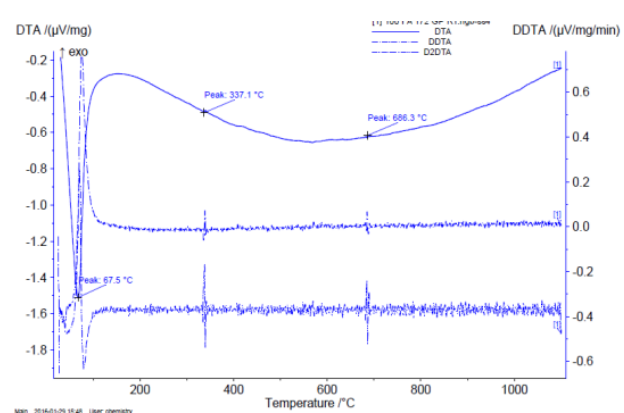

(a)

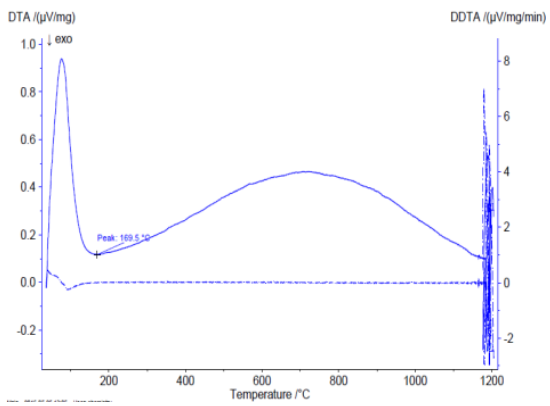

(b)

Fig. 4. (a) DTA and its derivatives of FAGP2; (b) DTA and its derivatives of FAGP2z

\subsection{Thermal conductivity and thermal expansion.}

Thermal conducivity value of FAGP 2 and FAGP $2 \mathrm{z}$ at $80^{\circ} \mathrm{C}$, and $800^{\circ} \mathrm{C}$ are about 1.7 and $0.3 \mathrm{~W} / \mathrm{m} . \mathrm{K}$ respectively and decreases with increasing tempeature. The thermal conductivity measurements exposed to temperature less than $120^{\circ} \mathrm{C}$ are only the function of conductivity of gel and the pores, at this temperature range most of the water evoporates, and hence pores in these can be assumed to contain only air.

The specimens cured at $80^{\circ} \mathrm{C}$ was used for dilatometric measurements which understand the thermal compatibility of the matrix and changing dimensions were noted after the attainment of thermal equilibrium. The coefficient of thermal expansion for the FAGP $2 \mathrm{z}$ are found to be the range $0.9-1.0 \times 10^{-6} /{ }^{\circ} \mathrm{C}$ in the temperature $250-800^{\circ} \mathrm{C}$. Further, it was about $2-2.5 \times 10^{-6} /{ }^{\circ} \mathrm{C}$ in the temperature below $200^{\circ} \mathrm{C}$. Test data on Portland cement mortar 
was found to be in the range $11-14.3 \times 10^{-6} /{ }^{\circ} \mathrm{C}$ in the $100-200^{\circ} \mathrm{C}$ and it was on higher value compared to that of geopolymer prepared.

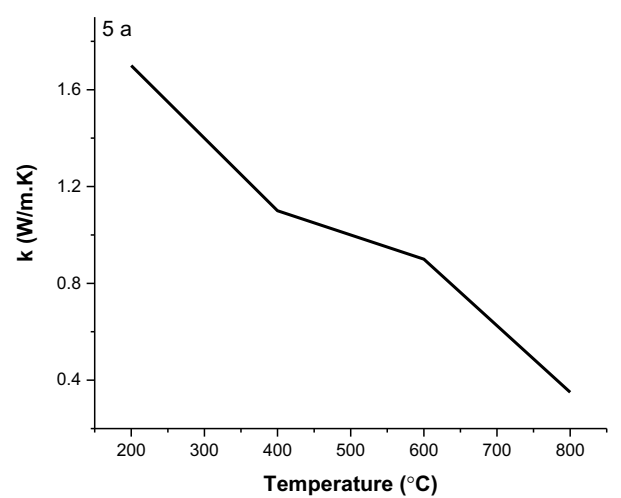

(a)

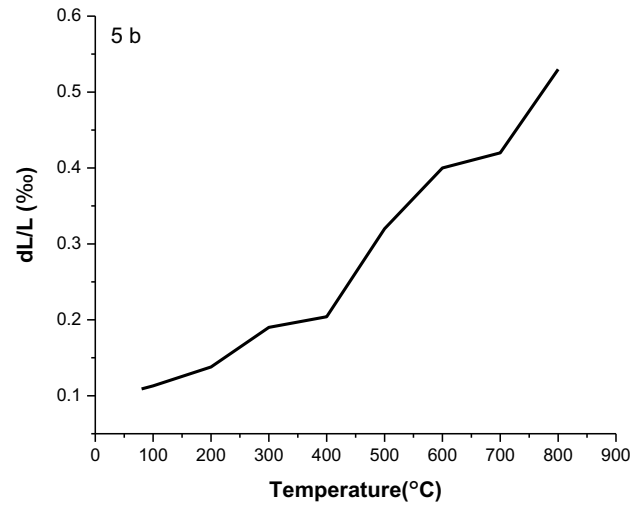

(b)

Fig. 5. (a) Thermal Conductivity at different temperature; (b) dL/Lo\%o of FAGP2 at different temperature.

The change in length for mortars after heating, the strain dL/Lo (\%o) was calculated. Figure 5(b) is a representative curve of FAGP2z. Minor expansion were observed in the geopolymer as temperature increased from 80 to 800 with the range of values $0.109 \mathrm{dL} / \mathrm{L}$ $\%$ to $0.53 \mathrm{dL} / \mathrm{L} \%$ without any drastic shrinkage. Literature cited in the both fly ash and metakaolin based geopolymers, was appreciable shrinkage below $100^{\circ} \mathrm{C}$ due to release of water and as temperature rises, between $300-700^{\circ} \mathrm{C}$ dehydroxylation of gels causes shrinkage and second shrinkage at above $800^{\circ} \mathrm{C}$ due to structural densification. [18-19]. However, the studied geopolymers with and without addition of $\mathrm{ZrO}_{2}$, has not shown any damage and negligible dimension change to the surface which may be due the lower adsorbed water on the surface of the gel.

\subsection{SEM analysis}

The Scanning Electron Microscopy of selected geopolymers before and after exposure are shown in the Figure 6, indicate distinct reaction product layers around the fly ash particle and the surface is more homogeneous with less porosity. At elevated temperature the rate of dissolution of the fly ash particle are enhanced and the condensation of alumino-silicate gel are obvious from the micrograph. The addition of zirconium di oxide after heating to $800^{\circ} \mathrm{C}$ shows compact and dense surface also the surface roughness has been reduced driven by surface tension thus resulting in good compressive strength. 


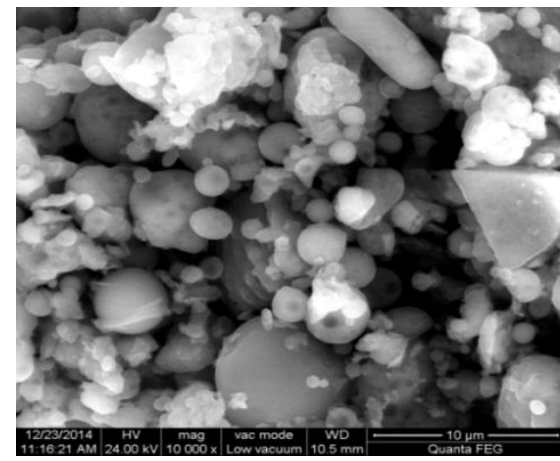

(a)

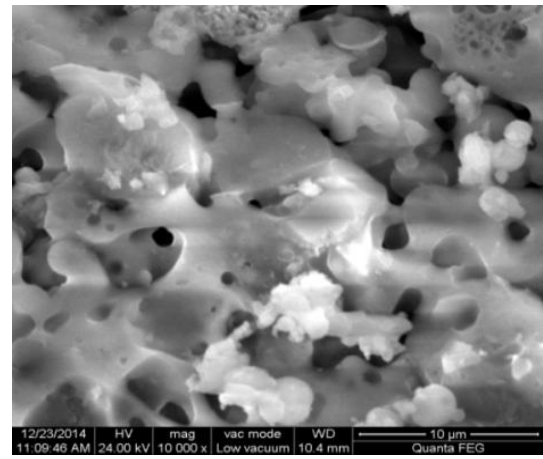

(b)

Fig. 6. SEM photograph of FAGP2 before (a) and after (b) thermal exposure $\left(800^{\circ} \mathrm{C}\right)$.

\section{Conclusions}

- In the current work geopolymer mortars prepared by using $100 \%$ Fly ash activated by the sodium silicate solution with final MR of $0.8(\mathrm{SiO} 2 / \mathrm{Na} 2 \mathrm{O}=0.8)$ experienced strength gaining at elevated temperature heating from $200-800 \mathrm{C}$ without any crack or shrinkage.

- Addition of $2 \%$ zirconium di oxide improved the thermal stability further without undergoing any thermal reaction at elevated temperature.

- Higher thermal conductivity values of FAGP2 with low linear thermal expansion indicates the faster rate of heat dissipation which may protect the skeleton of aluminosilicate gel.

Authors gratefully acknowledge financial support from Department of Science and Technology (DST) under grand no DST/TSG/STS/2012/20.

\section{References}

1. Joseph Davidovits, Geopolymer Chemistry and applications $3^{\text {rd }}$ edition (Geopolymer Institute)

2. M.W. Palomo, M.T. Grutzek, M.T. Blanco, Cem. Concr. Res., 29, 1323 (1999)

3. J.L. Provis, J.S.J. van Deventer, Geopolymers: Structures, Processing, Properties and Industrial Applications (2009)

4. C. Shi, P.V. Krivenko, D.M. Roy, Alkali-Activated Cements and Concrete (Taylor \& Francis, London and New York, 2006)

5. P. Duxson, A. Fernandez Jimenez, J.L.Provis, A.G.C. Lukey, Paloma, J.S.J. Van Deventer, J. Mater. Sci., 42, 2917 (2007)

6. A. Fernanez Jimenez, A. palomo, M. Criado, Cem. Concr. Res., 35, 120 ( 2005)

7. Chao Li, Henghu Sun, Longtu Li, Cem. Concr. Res., 40, 1341 (2010)

8. Q. Li, H. Xu, F. Li, P. Li, L. Shen, J. Zhai, Fuel, 97, 366 (2012)

9. M.M. Al Bakri, H. Mohammed, H. Kamarudin, I.K. Niza, Y. Zarina, J. Eng. Technol. Res., 3, 1 (2011)

10. J. Davidovits, M. Davidovits, N . Davidovits, U.S. Patent No, 5,342,595 (1994)

11. V.F.F. Barbosa, K.J.D. MacKanzie, Mater. Res. Bull., 38, 319 (2003)

12. Z. Pan, J.G. Sanjayan, B.V. Rangan, J. Mater. Sci., 44, 1873 (2009) 
13. T. Bakharev, Cem. Concr. Res., 36, 1134 (2006)

14. D.L.Y. Kong, J.G. Sanjyayan, K.S. Crentsil, Cem. Concr. Res., 3, 1583 (2007)

15. D.L.Y. Kong, J.G. Sanjyayan, Cem. Concr. Res., 40, 334 (2010)

16. Z. Sun, H. Cui, H. An, D. Tao, Y. Xu, J. Zhai, Q. Li, Constr. Build. Mater., 49, 281 (2013)

17. M.A. Villaquiran Caicedo, R.M. de Gutierrez, S. Sulekar, C. Davis, J.C. Nino, Appl. Clay. Sci., 118, 276 (2015)

18. J.L. Provis, C.Z. Young, P. Duxon, J.S. Van Devnter, Colloids. Surf. A Physicochem Eng. Asp., 336, 57 (2009)

19. P. Duxon, G.C. Lukey, J.S.van Deventer, J. Non-Cryst. Solids, 352, 5541 (2006) 